\title{
The Influence of Ndebele Cultural Practices on School Discipline in Two Secondary Schools in Mpumalanga Province; South Africa
}

\author{
Soane Joyce Mohapi \\ College of Education, University of South Africa, \\ Pretoria, South Africa \\ mohapsj@unisa.ac.za
}

\section{Doi:10.5901/mjss.2013.v4n11p376}

\section{Abstract}

There is no much research on how Ndebele cultural practices influences school discipline. This study investigated the influence of Ndebele cultural practices on school discipline.. Qualitative data were collected where two principals and two teachers from two rural secondary schools were interviewed and submitted written lived stories Partipants' narratives revealed that the two sample secondary schools were characterized by disciplinary problems ranging from absenteeism, late coming, learners especially boys not doing their home works, disrespectful and bullyiness. The findings of the study further indicated that Ndebele cultural practices rendered the two sample schools dysfunctional as results which affected learner performance. It has become clear, as set out in this paper, that the school discipline in a way may be influenced by cultural practices that are prevalent in Ndebele communities of the two rural secondary schools in the study. The study recommended strategies to ensure that Ndebele cultural practices contribute towards better functioning schools with less disciplinary problem.

Keywords: Teachers' narratives, school discipline, community and traditional leaders.

\section{Introduction}

The hallmark of an effectively functioning educational organization is an effective system of discipline for both teachers and learners (Phatlane 2001; Squelch 2000; Van Wyk 2000). Two schools selected in this paper experiences disciplinary problems which affected learner performance. Classroom disruption is a major impediment to learning ( Lorgat 2003). This paper aimed at showing how Ndebele cultural practices influence learning in the sampled schools. It is true that many studies on school discipline approach the problem from an almost fix-the kids approach (Walsh 1991; Good 1973; Savage 1991), it is the assumption of this paper that in part, the root cause of school discipline may be Ndebele cultural practices within the two communities. The problem of school discipline is as old as education itself and it dates back to the days of Socrates when discipline was regarded as a factor that hindered teaching and learning; Socrates wrote:

"Our youth now love luxuries. They have bad manners, and have contempt for authority. They shock, disrespect elders and they love to chatter instead of exercise. Children are now tyrants, not the servants of their households. They no longer rise when elders enter the room. They contradict their parents, chatter before company, gobble up their food, and tyrannize their teachers" (http//www.worldofquotes.com/author/Socrates/index.html).

These perceptions about learners are valid today as they were in the time of Socrates (Savage 1991). What is clear from the literature is that school discipline during twentieth century has become one of the most topical and contentious issue in education being commented upon by parents, educators, researchers, politicians and speakers at public forums but there is not much on how Ndebele cultural practices influence school discipline, this paper wants to close the gap.

\section{Ndebele Cultural practices}

The two schools in the study are in the former KwaNdebele homeland which is in the cultural heartland of Ndebele cultural practices. As is often the case in the traditional patriarchal African societies, Ndebele women do not enjoy the same social status as their male counterparts. Parents do not invest in the education of their daughters. They believe that they will be married during their adolescence and will then focus on raising family. Young girls are socialized into believing that males are born to be dominant over females and that they should not presume to compete with their male 
counterparts in any aspect of social life, as results girls are inclined to drop out of school before their education is completed, at certain point they absent themselves from school.. The practice of Iqude ${ }^{1}$ among the cultural Ndebele communities socializes young girls from puberty; between age ten to twelve years onwards into adult practices such as a good citizenship, child bearing, raising a family and the acquisition of general family nurturing skills. Obviously these cultural practices influence class attendance and school discipline.

Boys are also involved in cultural practices; their initiation which is called Ingoma ${ }^{2}$ is an Ndebele cultural practice which is followed to initiate boys into manhood and is a highly esteemed practice among Ndebele people. Boys between the ages eighteen to twenty one years are taken out into the bush or nearby mountainous terrain for a period of two months. Before the initiation is due to begin, the entire month is devoted to Ukukhanya ${ }^{3}$, which involves the preparation of the initiation. During the period the youths spend time together at night practicing songs and psyching themselves up for the most important event of their lives, which among other things will teach them how to live and behave as socially responsible men These practices often have disruptive effects on school discipline.

Boys find it difficult to observe school rules during Ukukhonga period, late coming becomes rife because their initiation tutors are usually unemployed men and have little regard for the boys' school commitments. Preparation for initiation continues until late at night, this denies the boys enough time to rest and do their home works. Boys become disrespectful to their teachers especially female or uninitiated male teachers. At the end of initiation period the families of the boys hold a huge graduation celebration called Ukuhlaba ${ }^{4}$ which happen after two months in the bush where boys have been initiated into all their cultural practices. The celebration parties continue for another month and cattle are slaughtered, family members present the celebrant with gifts. The period of Ukuhlaba is an acknowledgement of the manhood of these boys. They are encouraged to behave like men rather than boys they used to be before initiation. During the celebrations each youth has to announce his initiation or manhood name to his mother, sisters, and younger brothers. These names are derived from a respected list of names used to identify men who are from the initiation school. Time is usually taken off from school for the celebrations which result into long period of absence from school and had adverse effect on school discipline. After all the celebrations the boys ultimately should go back to school. Majority of them refuse to take instructions. The period of uncertainty lasts for months; while these boys thinking that they are men, trying to adjust to the realities of life that require them to be obedient to teachers irrespective of their age, gender and social standing as far as Ingoma is concerned.

Except the Ndebele cultural practices mentioned above, there are other factors that may influence school discipline; girls who are from initiation, "Iqude" become involved in unprotected sex with boys from the mountain, as results schools experience high pregnant rate of young girls and low learner achievement.

\section{African cultural practices and African self}

A number of social and cultural factors and practices have bearing on the self of Africans. Many young people give up their own education to take up jobs for sole purpose of being afraid of being punished at school. In polygamous home, children have different mothers but common father. Once the mother pass on, children face discrimination from remaining wife, this results in children running away from home and leaving school. Another factor is interdependence among African transcends death, while death terminates a person's visible physical presence in given space of time.

\section{Theoretical framework}

Bronfenbrenner's ecological model of human development underpinned this paper. This ecological perspective stresses the importance of understanding the relationship between the organism and various environmental systems (Hetherington; Parker 1993). Children are seen as active participants in creating their own environment. Bronfenbrenner's ecological model is multi-dimensional and it suggests that the level of interacting systems such as biological, psychological, social and cultural result in growth development and change (Smith et al 2003). Individuals and groups may be understood more clearly within different social context, as well as in terms of the way changes in the macro structures of the system influence those in the micro-systems (Swart; Pettipher 2005). The importance of Bronfenbrenner's ecological model in this paper is the premise that the ecological environment is set of four nested

\footnotetext{
1 Iqude is a Ndebele cultural activity that initiates girls into womanhood and responsibilities,this entails

2 Ingoma is a Ndebele cultural activity which initiates boys into manhood

3 Ukukhonga is one month preparation period during which initaiates psyche themselves up in preparation for initiation

4 Ukuhlaba is celebration after initiation. It signifies the completion of the traditional initiation ceremony
} 
systems, the most familiar is micro-system, that is what individual experiences in a given setting. For learners a microsystem may consist of the school's environment with teachers and learners, another micro-system may be the home environment with parents and the community. A home environment might affect the learner in its school performance, where cultural adherence comes into play.

\section{Delimitation of the study}

This study is of necessity a limited one and includes teachers employed at the two secondary schools in Nkangala district of Mpumalanga province; South Africa. The conclusions drawn from the study thus apply only to the above-mentioned population. The questions asked were designed specifically for the study. Given the reasonably small sample size, the findings of this paper cannot be randomly generalized to apply to all rural secondary schools and teachers. The paper aimed at achieving the following objectives:

- To understand and interpret teachers' stories

- To examine the influence of Ndebele cultural practices on school discipline

- To examine teachers 'perceptions about Ndebele cultural practices and school discipline

- To enlist teachers' recommendations

\section{Research method}

A Qualitative narrative approach was employed to explore on four rural secondary teachers' accounts of the influence of Ndebele cultural practices on school practices. Lieblich et al. (1998) divide approaches to narrative analysis along two axes: holistic-categorical and form-content. Riessman (2008) adds to this two more types of narrative analysis; the performative or dialogical aspect of narrative and visual narratives. In this paper the focus was on sequencing of themes within narratives, thus foregrounding the specifically narrative aspects of texts meaning (Squire 2008). The researcher focused on what participants said and their lived stories.

\section{Sample}

Permission was obtained from the relevant district of education department in Nkangala distric, the teachers themselves, school governing bodies and the principals. Anonymity was assured by using pseudonyms for the schools, teachers and the principals. Traditionally, secondary schools are judged on their performance in grade 12 results. The performance is thus used to measure the effectiveness and functionality of the school. The two schools in the study were consistently performing poorly and were characterized by disciplinary problems emanating from late coming, absenteeism, learners not doing their homework and stubbornness by boys. The performance of these two schools for the years 2007-2010 is indicated in annexure 1. The two schools thus provided spaces where an exploration of the influence of Ndebele cultural practices on school discipline could provide rich insights. Four participants; two from each school were invited to participate in the study. The researcher was given a permission to use a voice recorder.

\section{Ethical consideration}

After Regional director had given a permission for the two schools to participate in the study, the researcher arranged two meetings one at each school to make a presentation to the affected participants, the purpose of the study . The participants were informed about their right not to participate in the study if they feel like and that all ethical requirements will be adhered to; that is their names, and that of their schools will not be mentioned in the study.

\section{Data collection}

Semi structured interview and participants' stories were used. The study approached the problem from the perspective that Ndebele cultural practices are necessary but at certain point they affect school discipline. Semi structured interviews were used to explore certain aspects but also retained enough flexibility to allow participants to tell their $s$ experiences of working within Ndebele communities (Rossman \& Rallis, 1998). 


\subsection{Semi structured interviews}

Participants were asked the following key questions:

- When did they start teaching and were?

- How Ndebele cultural practices influenced school discipline?

- What are participants' perceptions on Ndebele cultural practices and school discipline?

\subsection{Teachers' Stories}

The researcher interacted well with the participants through conversation. Participants were requested to focus on four key issues when telling their stories; they were requested to write or tell their stories. All four participants told and wrote their lived stories.

- How many years of service in the school

- Their home

- How Ndebele cultural practices affected school discipline

- Their recommendation regarding school discipline and socio cultural practices

\section{Data analysis and findings}

The purpose of this paper is to explore how Ndebele cultural practices affect school discipline. Prior to the discussion on data analysis, an overview providing background information on issues relating to school discipline in the two schools were mentioned; poor learner performance, school environment, school management and governance.

\subsection{Poor learner performance}

Table 1: Pass rate for grade 12 in two schools

\begin{tabular}{|c|c|c|c|c|}
\hline SCHOOL & $\mathbf{2 0 0 7}$ & $\mathbf{2 0 0 8}$ & $\mathbf{2 0 0 9}$ & $\mathbf{2 0 1 0}$ \\
\hline A & $29 \%$ & $37 \%$ & $45 \%$ & $56 \%$ \\
\hline B & $17 \%$ & $40 \%$ & $52 \%$ & $60 \%$ \\
\hline
\end{tabular}

The above pass rate declares these schools dysfunctional. These schools could not reach $70 \%$ mark in the four years, which is a challenge to the departmental officials. School B managed to obtain $60 \%$ but this is far below the National average of $70 \%$. Ndebele cultural practices partly might be the cause of disruption of teaching and learning which led to poor performance of learners as indicated in table 1 above.

\subsection{Community involvement}

According to Fuller (1987) the school institution exerts a greater influence on learner achievement. Lack of proper measures to manage school discipline may affect learner performance. Although the two schools might have proper system of managing disruption behavior, schools cannot act against traditions and culture. The schools had no power not to refuse learners to be part of their cultural practices, the whole community is involved. What is puzzling is when the schools call parents to school meetings, the turn up is very low as compared to high participation of community members in their cultural practices.

\subsection{School management and governance}

Haddad et al (1990) note that well managed, effective schools share several characteristics, they display and orderly environment and emphasize academic achievement. Although in the two schools South African Schools' Act allow them to deal with any disruptive behavior, they find it difficult when these disruptive behaviors are caused by culture 


\subsection{Findings from semi structured interviews}

\subsubsection{Year participants started teaching}

With regard to the year participants started teaching, data revealed that all participants had more than ten years working in KwaNdebele area; one participant started in 1989, another one in 1990 and two in 1994.

The following graph represent the years the participant started teaching in KwaNdebele:

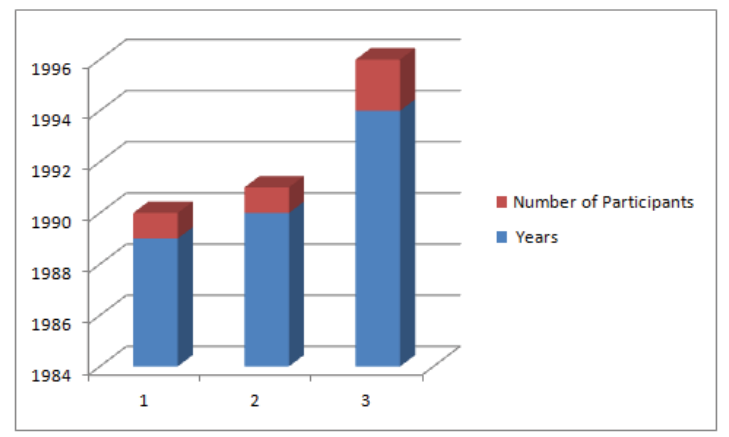

Based on their years serving in the two communities, it seems in all these years, participants had experienced how Ndebele cultural practices affected school discipline.

\subsubsection{How Ndebele cultural practices influenced school discipline?}

When asked how Ndebele cultural practices influence school discipline participant A responded by saying that boys who are from the mountain are stubborn, they do not what to do their homework and it causes disciplinary problems, some learners feel is not necessary to do the homework. Participant B felt that girls think they are matured they sleep with elder men and fell pregnant, as result they continuously become absent, because of their visits to the clinics for check up. They have little time for school work said participant $B$. participant $C$ and $D$ said learners become disrespectful.

\subsubsection{Participants' perceptions on Ndebele cultural practices and school discipline}

Participants felt that they do not have power any more, since the abolishment of corporal punishment, learners do as they wish. One participant said:

\section{"When I was young are was afraid of the teachers"}

Taking an overview of the participants' responses, poorly disciplined learners are prone to lose interest in their schoolwork and neglect their studies, and destroy their teacher-learner relationship. It also happened with girls in the two schools, those who initiated from "Iqude", they continuously became absent and saw themselves as future mothers. Their parents also encouraged them to sleep with men of which some of them they fall pregnant at early age.

\subsection{Teachers' stories}

Teachers were able to tell the researchers about their years of service in the school, their home, how Ndebele cultural practices affected school discipline and their recommendation regarding school discipline and Ndebele cultural practices

\subsubsection{Years of service}

From what the participants said, it was noted that participant A taught for 24 years, participant B for 23 years and participant $\mathrm{C}$ and $\mathrm{d} 19$ years. 


\subsubsection{Participants' home}

From the participants' lived stories, it was noted that none of the participants are staying in the village they are teaching. They travelled to and fro to work. The reason might be that they are afraid to be scolded by their learners who initiated from the mountain school, or they do not feel comfortable to stay among Ndebeles due to their cultural practices

\subsection{How Ndebele cultural practices affected school discipline}

Participant B told the researcher that he hated the period prior Ndebele initiation schools. Learners, both girls and boys do not come to schools regularly, people are afraid to walk at night and no one is allowed to speak bad about "Ingoma", that is why he opted not to stay in the community where he is teaching. Participant $C$ emphasized that from his experience working within KwaNdebele community, he realized that parents respect and love their culture at the expense of their learners' education. From what participant D and a said, that despite the fact that South African Schools' Act allow each school to have Code of conduct of learners, no teacher will use the Code of Conduct to correct learner behavior which was as the results of Ndebele cultural practices.

\subsection{Participants' recommendations}

Common thread that runs through this paper is that participants have all been exposed to Ndebele cultural practices hence they recommended that initiation ceremonies should take place during school holidays, and that the duration is too long it must be reduced from three months to two weeks. Learners should be given a chance to complete grade 12 before going for initiation school

\section{Discussion}

The central argument of this paper is that certain Ndebele cultural practices affect school discipline. The qualitative data analysis and interpretation revealed that certain Ndebele cultural practices do influence school discipline. It became evident to the researcher that participants are encountering disciplinary challenges in their schools and classes and this can be attributed to Ndebele cultural practices.

When referring to qualitative research results, theoretical frame work and literature study on Ndebele cultural practices, and relating these to the influence of Ndebele cultural practices on school discipline, the researcher conclude that participants are challenged to deal with disruptive learner behavior caused by Ndebele cultural practices. This is also supported by participants' years of experience of working in the Ndebele community. Researcher assumed that for participants, working in the Ndebele communities was not pleasant. They were exposed to disrespectful learners who prioritized their cultural practices over their education. The community and their parents supported them. The micro system as explained by Bronfenbrenner's ecological model, played a role in affecting how learners should behave. It is interesting therefore to note that participants respect Ndebele cultural practices, and become frustrated when it disrupt teaching and learning.

From what the participants said, it seemed that they have no hope that they will be respected by boys who are form the mountain. One participant fell it was better for him to relocate to nearby town to avoid being scolded by boys coming from initiation school.

It was further understandable that participants recognized that the school discipline is a challenge. It was noted that most of the participants suggested recommendations on how cultural practices in the two communities may contribute towards school effectiveness with less disciplinary problems if these practices happened during school holidays were teaching and learning are not disrupted, communities should move away from organizing these practices for longer period and they should adopt an approach which is clearly focused on building a sustainable positive relationship with School management and community. Because when learners use these cultural practices as a weapon of disrespecting school management and school rules, teachers feel lost and have subsequently lost hope in maintaining school discipline. It was also mentioned by two participants that as teachers are responsible for children future and that although cultural practices instil a sense of responsibilities to those who are initiated, celebrants should be responsible, while celebrating their achievement of attaining manhood, they must start doing their school work.

This is confirmed in the following statement: 
"Be responsible for yourself and allow kids to take responsibility for themselves" (http://www.ascd.org/readingroom/books/curwin99book.html).

\section{Recommendations}

Based on the findings from the study; the researcher support recommendations by the participants. The researcher also recommends:

- Planning of Ndebele cultural practices should be communicated to school management

- To think of having these practices during schools holidays

- The celebration to take place during weekends

- Tutors of initiation schools to emphasize respect by the graduates to their parents, teachers and any senior person regardless of his/her social standing.

- Graduates to understand and know that school environment while different from initiation school support and complement all what will occur during initiation period.

- To allow learners to complete their grade 12 before going for initiation schools

\section{Conclusion}

Conclusions reached are derived from research findings. The conclusions drawn indicate that Ndebele cultural practices impact on school discipline. Participants acknowledged that Ndebele culture need to be respected and adhered to, but it must not cause disciplinary problems. The findings in this paper raised many questions that suggest a need for further research. It must be acknowledged that many aspects of this study could be replicated with other participants to determine whether or not the themes identified here hold true for the participants in other settings.

This study was able to determine were elements assisted in answering the research problem and addressing the research objective. One of the positive finding is that Ndebele cultural practices either positive or negative, affect school discipline and happened within Ndebele people. Although this finding, this study appears to be one of the first to confirm this assumption. Further study using other methods would help to confirm or refute this finding. In the pursuit of more information and knowledge, a similar study could be undertaken where the stated limitations of this study are with regard to sample size in respect of the number of schools and teachers involved in the study are addressed.

It might also be important determine the correlation between discipline carried out at initiation school and the one that is implemented in schools. There is definitely incongruence between what happens at home during the initiation period and at the school that might merit a study. It could also be determined how the disconnection affects school discipline .Considering the finding and my observation in this study; I conclude that Ndebele cultural practices have a varying impact on school discipline.

\section{References}

Fuller B 1987. What School factors Raise Achievement in the Third World?. Review of Educational Research 57(3): $255-292$.

Haddad WD; Carnoy M; Rinaldi R; Regel O 1990. 'Education and Development: Evidence for New Priorities'. World Bank Discussion Paper no 95.

Hetherington EM; Parker RD; 1993. Child Psychology: A Contemporary Viewpoint. New York: McGraw-Hill

http://www.answers.com/topic/school-discipline-1).

http//www.worldofquotes.com/author/socrates/index.html

http//www.worldofquotes.com/author/socrates/index.html

http://www.ascd.org/readingroom/books/curwin99book.html

Liblich

Lorgat H; August 2003. How to Beat Corporal Punishment. The Teacher's Voice. vol 7 no. 7. Pietermaritzburg: The Natal Printing and Publishing Company (PTY) LTD

Phatlane RS. 2001. "The Impact of the Abolition of Corporal Punishment on Disadvantaged Urban Secondary Schools" M.Ed. Dissertation, University of Pretoria.

Riessmann

Rossman GB; Rallis SF1998. Learning in the field. An Introduction to Qualitative research. Thousand Oaks, Ca: Sage

Savage TV 1998. Discipline for Self Control. New York: Prentice Hall.

Slee R 1988. Discipline for Character Development. Birmingham: Rep Books

Smith CJ; Laslett R 1998. Effective Classroom Management: teachers' Guide. London: Rouledge

South African Schools Act number 84 of 1996. Pretoria: Government printers. 
Squelch JM 2000. Discipline. Pretoria: Centre for Education, Law and Policy(CELP)

Swart E; Pettipher R 2005. 'A Framework for Understanding Inclusion' In Landsberg E; Kruger P; Nel N (eds). Addressing Barriers to Learning. A South African perspective. Pretoria: Van Schaick

Van Wyk ER 2000. "Positive Discipline. New Approach to Discipline" D.Ed Thesis University of Pretoria

Walsh K 1991. Discipline for Character Development. Birmingham: REP Books

Iqude is a Ndebele cultural activity that initiates girls into womanhood and responsibilities,this entails Ingoma is a Ndebele cultural activity which initiates boys into manhood

Ukukhonga is one month preparation period during which initaiates psyche themselves up in preparation for initiation

Ukuhlaba is celebration after initiation. It signifies the completion of the traditional initiation ceremony 